\title{
A Case of Late Diagnosed Multiple Pilar Leiomyoma Located on the Cheek and Neck
}

\author{
Nursel Dilek ${ }^{*}$, Yunus Saral1, Özgür Sadık Kotan1, Recep Bedir ${ }^{2}$ \\ ${ }^{1}$ Dermatology Department, Recep Tayyip Erdoğan University, Medical Faculty Hospital, Rize, Turkey \\ ${ }^{2}$ Pathology Department, Recep Tayyip Erdoğan University, Medical Faculty Hospital, Rize, Turkey \\ Email: nur.dilek@hotmail.com
}

Received 10 January 2014; revised 17 February 2014; accepted 15 March 2014

Copyright (C) 2014 by authors and Scientific Research Publishing Inc.

This work is licensed under the Creative Commons Attribution International License (CC BY).

http://creativecommons.org/licenses/by/4.0/

(c) (i) Open Access

\begin{abstract}
Leiomyomas are benign soft tissue neoplasms that arise from muscles. Skin is the second most common location for leiomyoma and often localized on the trunk or extremities. Less than $1 \%$ of leiomyomas happen in the head and neck. Here we report a case of pilar leiomyoma which located on the face and neck in the form of multiple, large papulonodules plaque. The treatment by excision and grafting would be difficult because of the large surface area involved the patient was treated with nifedipine. We recommend that leiomyomas must be included in the clinical differential diagnosis of painful papulonodules.
\end{abstract}

\section{Keywords}

Leiomyoma, Neoplasm, Cheek, Neck

\section{Introduction}

Leiomyomas are benign soft tissue neoplasms that arise from vascular, arrector pili, genital, and mamillary smooth muscles [1] [2]. Skin is the second most common location for leiomyoma after uterus which accounts for $95 \%$ of cases [1]. The lesions usually present as red-brown nodules may range in size from 2 to $20 \mathrm{~mm}$ in diameter and the patients suffer from spontaneous severe pain attacks [2]-[4]. In addition, the lesions may be sensitive to cold exposure or light touch [5]. Cutaneous leiomyoma is often localized on the trunk or extremities, less than $1 \%$ of leiomyomas happen in the head and neck [4] [6]. Piloleimyomas are the most common type of cutaneous leiomyoma arising from arrectores pilorum and can present as either a solitary nodule or multiple lesions [7] [8]. Herein, we report a case of pilar leiomyoma which located on the face and neck in the form of multiple, large papulonodules plaque.

"Corresponding author.

How to cite this paper: Dilek, N., et al. (2014) A Case of Late Diagnosed Multiple Pilar Leiomyoma Located on the Cheek and Neck. Pain Studies and Treatment, 2, 27-30. http://dx.doi.org/10.4236/pst.2014.22006 


\section{Case Report}

A 57-year-old male patient presented with painful nodular lesions on the left cheek and neck. He first noted the lesions at age 16. Topical therapy (unknown) in the form of cream from time to time previously applied in different centers but the patient's complaints undiminished. Lesions had increased in size and number for the past 31 years. The lesions were cosmetically disfiguring because of their location and painful particularly in the winter months. A family history was questioned but the patient did not have any famaly history. His physical examination demonstrated approximately 50 reddish-brown, firm, painful with touching, well circumscribed nodules measuring 5 - $15 \mathrm{~mm}$ on the left cheek and neck (Figure 1). Histopathological examination of the excised nodule showed proliferation of smooth muscle bundles in an interlacing configuration in the upper dermis (Figure 2). Immunohistochemical studies were performed and the cells were strongly positive for smooth muscle actin (SMA) (Figure 3). According to macroscopic and histological findings, diagnosis of piloleiomyoma was made. In addition to cosmetic concerns, the treatment by excision and grafting would be difficult because of the large surface area involved. The patient was treated with $90 \mathrm{mg}$ nifedipine once daily for 4 weeks and cold prevention recommended. At the end of 4 weeks, the patient's complaints decreased. It was decided to start the treatment with nifedipine at the onset of the cold weather.

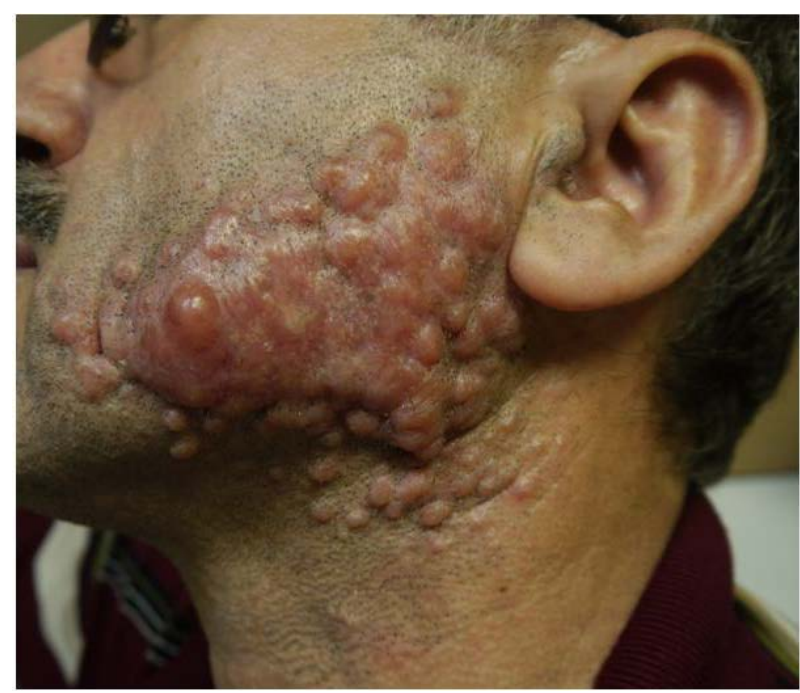

Figure 1. Reddish-brown, well circumscribed nodules on the left cheek and neck.

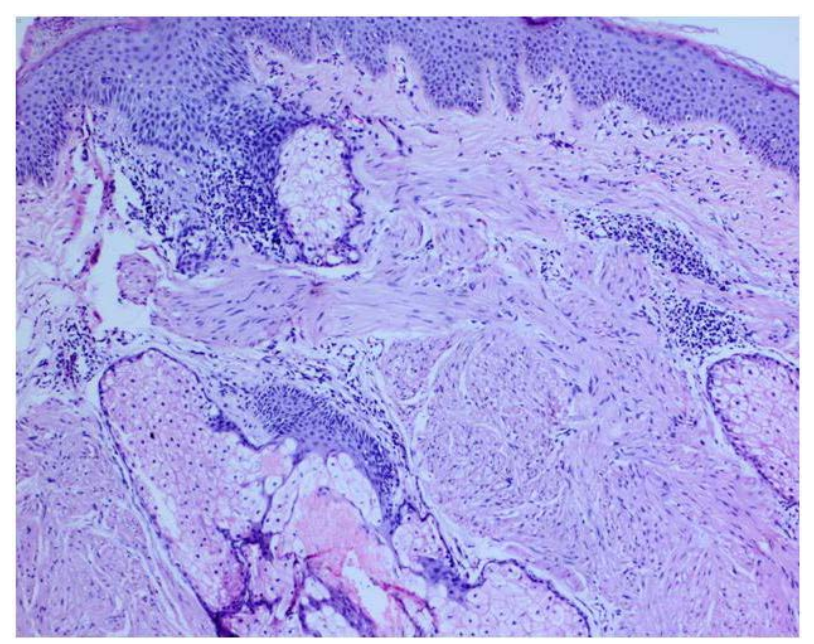

Figure 2. Benign smooth muscle fibers between pilosebaceous glands in the upper dermis (H \& E ×100). 


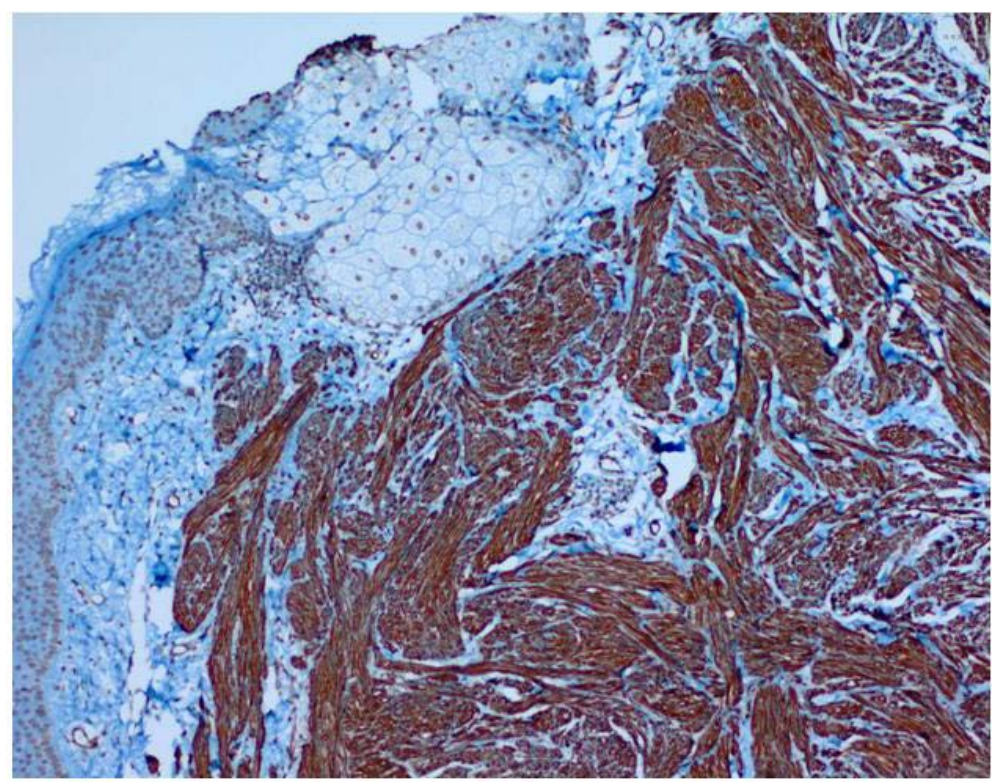

Figure 3. The cells strongly positive for smooth muscle actin (SMA) $(\times 100)$.

\section{Discussion}

Leiomyoma is a benign tumour commonly encountered in the genitourinary and gastrointestinal organs in adults [9]. Cutaneous leiomyomas are uncommon, painful benign smooth muscle neoplasms and more common in adults than in children and comprise approximately 5\% of all leiomyomas [1] [10]. Anatomic distribution of cutaneous leiomyomas is wide and they can present clinically as either solitary or multiple lesions that have a skin colored or reddish surface and are most commonly located on the extremities [10]. Piloleiomyoma is the most common type of cutaneous leiomyomas [7]. In contrast to the mainly solitary angioleiomyomas, piloleiomyomas predominantly manifest as multiple tumors [11]. Pilar leiomyomas are unencapsulated, circumscribed dermal tumors composed of numerous fascicles of smooth muscle in an interlacing and whorled arrangement and the precise etiology of this disease is still unknown [4] [7]. Treatment is often requested due to ongoing symptoms. Topical treatment procedures such as nitroglycerine paste, lignocaine, phentolamine and systemic treatment procedures with alpha blockers, calcium-channel blockers, glyceryl trinitrate, antidepressants and analgesics have been used [5]. Calcium-channel blockers have been effective in our patient. While solitary lesions may be easily treated by surgical excision, multiple lesions covering large areas as in our patient are more difficult to manage [12].

\section{Conclusion}

Cutaneous leiomyomas are rare lesions and there is limited literature on its clinicopathologic features. As in our patient, multiple leiomyomas confined to the cheek and neck are an unusual clinical presentation. We recommend that leiomyomas must be included in the clinical differential diagnosis of painful papulonodules in order to differentiate them from dermatofibroma, neurofibroma, nodular fasciitis, fibromyoma, and smooth muscle hamartoma.

\section{Conflict of Interest}

The authors declare that they have no conflict of interest.

The article has not been published or submitted for publication elsewhere.

\section{References}

[1] Malhotra, P., Walia, H., Singh, A. and Ramesh, V. (2010) Leiomyoma Cutis: A Clinicopathological Series of 37 Cases. Indian Journal of Dermatology, 55, 337-341. 
[2] Akay, B.N., Boyvat, A., Heper, A.O. and Unlu, E. (2008) Congenital Pilar Leiomyoma. Journal of American Academy Dermatology, 59, 102-104.

[3] Hauschild, A., Maier, C. and Christophers, E. (1997) Multiple Painful Leiomyomas of the Skin: A Novel Therapy with Sympathicolysis. Journal of European Academy Dermatology and Venereology, 9, 262-265.

[4] Matthews, J.H., Pichardo, R.O., Hitchcock, M.G. and Leshin, B. (2004) Cutaneous Leiomyoma with Cytologic Atypia, Akin to Uterine Symplastic Leiomyoma. Dermatological Surgery, 30, 1249-1251.

[5] Lun, K.R. and Spelman, L.J. (2000) Multiple Piloleiomyomas. Australas Journal of Dermatology, 41, 185-186.

[6] Cintra, P.P., Lima, W.T. and Rodrigues, J.A. (2007) Leiomyoma of the Nasal Cavity: Case Report. Brazilian Journal of Otorhinolaryngology, 73, 851.

[7] Sada, A., Misago, N., Inoue, T. and Narisawa, Y. (2007) Segmental Multiple Cutaneous Piloleiomyoma with an Overlying Epidermal Proliferation. Journal of Dermatology, 34, 665-667.

[8] Pileri, A., Ghetti, P.L., Neri, I., Raone, B., Ciabatti, S., Reggiani, C. and Patrizi, A. (2011) Atypical Piloleiomyoma of the Face Presenting with Central Ulceration. Dermatology Reports, 3, 112.

[9] Yamato, M., Nishimura, G., Koguchi, Y. and Saotome, K. (1999) Calcified Leiomyoma of Deep Soft Tissue in a Child. Pediatrical Radiology, 29, 135-137.

[10] Fons, M.E., Bachhuber, T. and Plaza, J.A. (2011) Cutaneous Leiomyosarcoma Originating in a Symplastic Pilar Leiomyoma: A Rare Occurrence and Potential Diagnostic Pitfall. Journal of Cutan Pathology, 38, 49-53.

[11] Badeloe, S., van Geel, M., van Steensel, M.A., Bastida, J., Ferrando, J., Steijlen, P.M., Frank, J. and Poblete-Gutiérrez, P. (2006) Diffuse and Segmental Variants of Cutaneous Leiomyomatosis: Novel Mutations in the Fumarate Hydratase Gene and Review of the Literature. Experimental Dermatology, 15, 735-741.

[12] Christenson, L.J., Smith, K. and Arpey, C.J. (2000) Treatment of Multiple Cutaneous Leiomyomas with CO2 Laser Ablation. Dermatological Surgery, 26, 319-322. 